\title{
Is Femoral Nerve Block Useful for Decreasing Postoperative Delirium in Hip Arthroplasty?
}

\author{
Jong seok Baik, MD, Suc hyun Kweon*, MD, Jin sung Park, MD, Young chang Lee, MD \\ Department of Orthopedic Surgery, Wonkwang University School of Medicine, Iksan, Korea \\ *Corresponding author: Suc hyun Kweon, Muwang-ro 895, Iksan, Jeonbuk, Korea, Department of Orthopaedic Surgery, \\ School of Medicine, Wonkwang University, Korea
}

\begin{tabular}{|c|c|}
\hline ARTICLE INFO & ABSTRACT \\
\hline Received: 慧 May 21, 2020 & Citation: Jong seok Baik, MD, Suc hyun Kweon, MD, Young chang Lee, M.D and Jong \\
\hline Published: 幽 July 02, 2020 & $\begin{array}{l}\text { seok Baik, M.D. Is Femoral Nerve Block Useful for Decreasing Postoperative Delirium in } \\
\text { Hip Arthroplasty?. Biomed J Sci \& Tech Res 28(4)-2020. BJSTR. MS.ID.004684. }\end{array}$ \\
\hline
\end{tabular}

\section{Introduction}

Delirium, which is one of the complications that may occur after surgery, involves a rapid occurrence and fluctuation of disturbed consciousness and impaired orientation, memory, thinking, perception, and behavior, and serious changes occur throughout the day. Age is the most well-known risk factor for delirium, where the incidence of delirium significantly increases among elderly patients aged 65 years or older, ranging from 13-61\% [1-3]. Delirium in elderly patients increases mortality, increases healthcare cost, prolongs hospital stay, and undermines quality of life $[3,4]$. Hip fracture can frequently occur in the elderly, and delirium in the perioperative period may lead to more serious outcomes. The risk of delirium was reported to be higher if pain from hip fracture is not controlled [5], and so various measures, such as drugs including NSAIDs and opioids, nerve block, and intraarticular injection, are used to control postoperative pain. Andrew et al. reported that the incidence of delirium remained high even with the use of a lowdose opioid in patients with acute pain, such as those with hip fracture, and suggested that considering that a high-dose opioid is a risk factor for delirium, failure to manage acute pain can actually increase the risk of delirium [6]. As previously mentioned, multiple studies have reported that old age is a risk factor for postoperative delirium, and other related factors have also been identified. However, there was no study examining the effects of reducing

pain through preoperative femoral nerve block on the incidence of delirium. Thus, we aimed to investigate the effects of preoperative femoral nerve block on pain control, amount of analgesics used, and incidence of delirium in elderly patients diagnosed with proximal femur fracture.

\section{Subjects and Methods}

This prospective study was approved by the institutional review board at Wonkwang University hospital, and 286 patients aged 65 years or older who had been diagnosed with proximal femur fracture and treated with surgery(Hemiarthroplasty or Totalarthroplasty) between May 2016 and December 2017 were enrolled. All patients were admitted through the emergency department or outpatient clinic, and the Mini-Mental state Examination Korea (MMSE-K) were investigated before surgery. After excluding patients diagnosed with dementia or Parkinson's disease or with a MMSE-K score of below 15 and patients who underwent general anesthesia for being contraindicated for spinal anesthesia, a total of 130 patients were double-blinded randomized into two groups. Group $\mathrm{A}(\mathrm{n}=65)$ received both preoperative femoral nerve block by an anesthesiologist and patient-controlled analgesia (PCA), and group B(n-=65) only received postoperative PCA (Figure 1). 

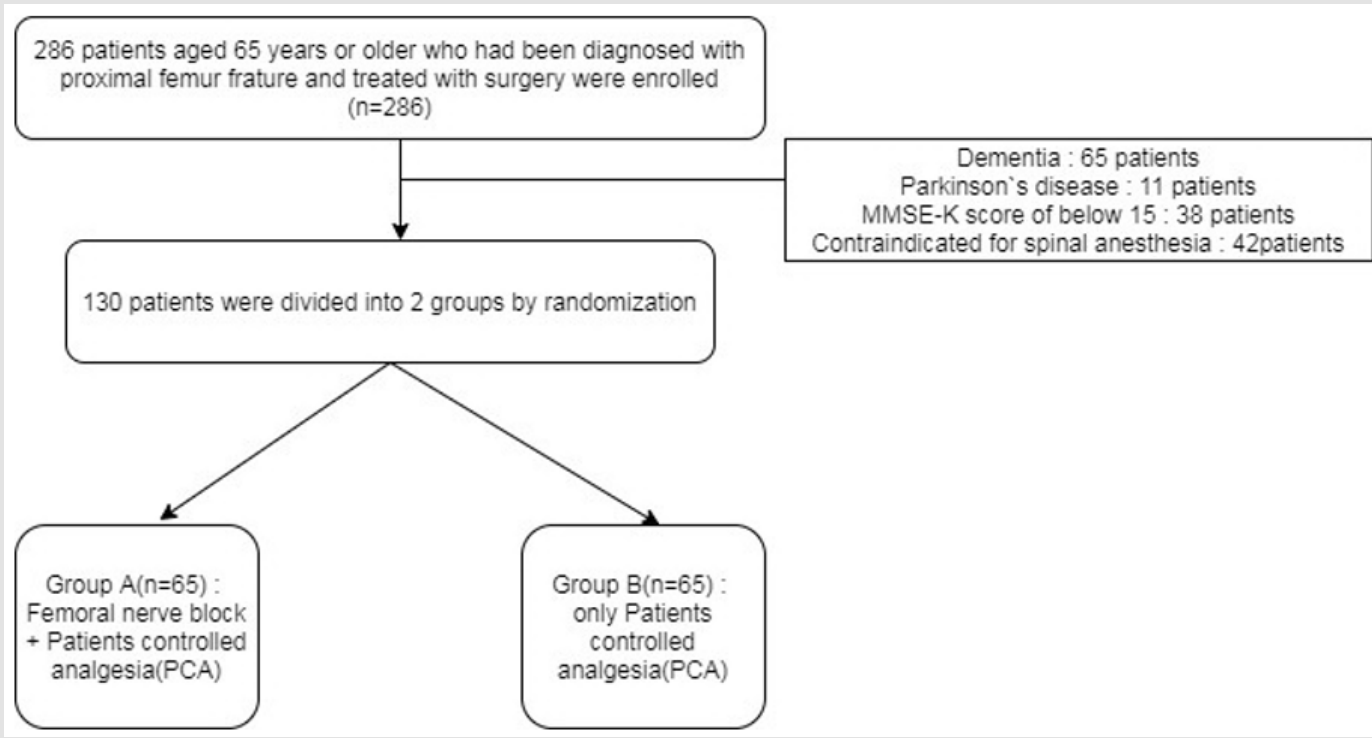

Figure 1: Operation Chart.

All femoral nerve block procedures were performed with ultrasound guidance by an experienced anesthesiologist. The HS50 (Samsung Medison Inc, Seoul, Korea) ultrasound system was used, and the procedural site (groin area) was prepared with chlorohexidine or betadine. The femoral nerve was confirmed using a 2-inch, 21-gauge stimuplex needle with a Stimuplex nerve stimulator (B. Braun Medical Inc, Bethlehem, PA). After palpating the femoral artery, the needle was injected 1-1.5 cm lateral to the pulse using a sterile technique. The assistant repeatedly performed regurgitation every time the position of the needle was altered to prevent intravascular injection. The nerve stimulator was set to 1-1.5 $\mathrm{mA}$ and the needled was injected until femoral muscle contraction was observed. Femoral muscle contraction was confirmed by observing quadriceps femoris spasm and upward movement of the patella. First, 20 cc of $0.75 \%$ ropivacaine was injected into the femoral perineurium. Continuous nerve block was maintained by infusing $10 \mathrm{ml}$ of $0.2 \%$ ropivacaine in 6 -hour intervals until postoperative day3 (POD3).

For PCA, three $100 \mathrm{mcg} / 2 \mathrm{ml}$ fentanyl citrate amps were infused and five $20 \mathrm{mg} / 2 \mathrm{ml}$ Acupan (Nefopam $\mathrm{HCl}$ ) amps, three $30 \mathrm{mg} / 1 \mathrm{ml}$ Ketocin (ketorolac tromethamine) amps, and one $4 \mathrm{mg} / 1 \mathrm{ml}$ onsentron (ondansetron) amp were mixed and infused for three days. PCA was applied equally for both groups. For both groups, oral NSAIDs were used for postoperative pain control. After surgery, delirium was diagnosed by differentiating between simple cognitive decline or depression based on the confusion assessment method (CAM) and examination with a psychiatrist. If symptoms deflecting delirum such as acute onset of mental changes and fluctuating course, inattention, disorganized thinking and altered levels of consciousness, immediate call was made to psychiatrist.
The total amount of pain-control agents used after surgery was compared. Fentanyl citrate is first choice of our hospital. If fentanyl citrate was not used due to allergy or hypersensitivity, morphine sulfate or hydromorphone was used. Morphine sulfate or hydromorphone doses were converted to fentanyl citrate using the formula: $1 \mathrm{mg}$ of morphine $=10 \mathrm{mcg}$ of fentanyl citrate, $1 \mathrm{mg}$ of hydromorphone $=50 \mathrm{mcg}$ of fentanyl citrate [7]. Pain was evaluated with the visual analogue score (VAS), and it was measured once before surgery and once a day on POD 1, 2, and 3. Further, the presence of postoperative complications was also assessed.

The normality tests of the distributions of the variables were performed using Shapiro-Wilk normality test. Chi-square tests were used for the categorical variables. Wilcoxon test was used for the analysis of the abnormality distributed variables. Statistical analysis was performed using R Statistical Software (Foundation for Statistical Computing, Vienna, Austria) and defined as significant when $\mathrm{p}<0.05$.

\section{Result}

There were no significant differences in hematologic data and medical history, such as MMSE-K between the two groups (Tables 1 \& 2). Postoperative delirium occurred in 6 patients $(9.23 \%)$ in group $A$ and 16 patients $(24.62 \%)$ in group $B(p=0.019$, Odds ratio $=3.211$ ). The mean VAS on POD 1 was $4.91 \pm 0.74$ in group $A$ and $5.63 \pm 0.87$ in group $\mathrm{B}(\mathrm{p}<0.05)$. On POD 2 , the mean VAS was $4.17 \pm 0.70$ and $4.75 \pm 0.79(\mathrm{p}<0.05)$, respectively, on POD3, the mean VAS was $3.47 \pm 0.66$ and $3.89 \pm 0.67(\mathrm{p}<0.05)$, respectively. VAS significantly differed between the two groups whole time period. The amount of opioids used after surgery statistically significantly differed between the two groups, with an average of $131.6 \pm 39.1$ mcg in group $\mathrm{A}$ and $181.8 \pm 49.0 \mathrm{mcg}$ in group $\mathrm{B}(\mathrm{P}<0.05)$ (Table 3$)$. 
Table 1: Preoperative demographics of patients in groups A and B.

\begin{tabular}{|c|c|c|c|}
\hline & Group A(n=65) & Group B(n=65) & P value \\
\hline Age & $77.3 \pm 9.82$ & $79.1 \pm 7.89$ & 0.538 \\
\hline Sex (Male: Female) & $21: 44$ & $19: 46$ & 0.432 \\
\hline ASA(I/II/III/IV) & $1 / 20 / 37 / 7$ & $2 / 22 / 37 / 4$ & 0.394 \\
\hline DM & $27(41.5 \%)$ & $31(47.7 \%)$ & 0.691 \\
\hline HTN & $47(72.3 \%)$ & $48(73.8 \%)$ & 0.549 \\
\hline $\begin{array}{c}\text { Operation (Hemi/ } \\
\text { Total-arthroplasty) }\end{array}$ & $45 / 20$ & $50 / 15$ & 0.243 \\
\hline MMSE-K & $21.5 \pm 2.87$ & $22.6 \pm 3.41$ & 0.313 \\
\hline
\end{tabular}

Table 2: Preoperative hematologic data of patients in groups A and B.

\begin{tabular}{|c|c|c|c|}
\hline & Group A(n=65) & Group A(n=65) & P value \\
\hline $\mathrm{Hb}(\mathrm{g} / \mathrm{dL})$ & $9.1 \pm 3.5$ & $9.4 \pm 2.7$ & 0.124 \\
\hline Hematocrit (\%) & $43.4 \pm 2.7$ & $42.7 \pm 2.4$ & 0.253 \\
\hline Albumin(g/dL) & $3.25 \pm 1.17$ & $3.47 \pm 2.57$ & 0.224 \\
\hline Uric acid(mg/dL) & $3.7 \pm 1.1$ & $3.2 \pm 2.1$ & 0.324 \\
\hline ESR (mm/Hr) & $26 \pm 2.5$ & $28 \pm 2.7$ & 0.08 \\
\hline CRP (mg/L) & $45.7 \pm 10.5$ & $36.8 \pm 7.8$ & 0.126 \\
\hline $\begin{array}{c}\text { Procalcitonin(ng/ } \\
\mathrm{mL})\end{array}$ & $0.02 \pm 0.05$ & $0.04 \pm 0.07$ & 0.484 \\
\hline
\end{tabular}

Table 3: Perioperative pain and amount of opioids used for patients in groups A and B.

\begin{tabular}{|c|c|c|c|}
\hline & Group A(n=65) & Group B(n=65) & P value \\
\hline Delirium & $6(9.23 \%)$ & $16(24.62 \%)$ & $\mathrm{P}=0.019$ \\
\hline \multicolumn{4}{|c|}{ Preoperative VAS } \\
\hline POD 1 & $4.91 \pm 0.74$ & $5.63 \pm 0.87$ & $\mathrm{p}<0.05$ \\
\hline POD 2 & $4.17 \pm 0.70$ & $4.75 \pm 0.79$ & $\mathrm{p}<0.05$ \\
\hline POD 3 & $3.47 \pm 0.66$ & $3.89 \pm 0.67$ & $\mathrm{p}<0.05$ \\
\hline Post-op opioid(mcg) & $131.6 \pm 39.1$ & $181.8 \pm 49.0$ & $\mathrm{p}<0.05$ \\
\hline
\end{tabular}

\section{Discussion}

In this study, we found that the femoral nerve block group was more effective than the control group in pain improvement and opioid use level reduction until POD 3. In addition, there was a significantly lower probability of delirium in the femoral nerve block group compared to the control group. Extreme pain after hip fractures increases morbidity, which is a high-risk factor for delirium. It is associated with prolonged hospital stay, slower to mobilize, and poor health-related quality of life $[5,8,9]$. One of the major complications after surgery for elderly hip fractures is delirium, which is associated with poor outcomes such as impaired functional and cognitive recovery, increased hospital length, higher costs, and increased mortality [10]. The mechanisms that cause delirium are not exactly explained, but postoperative pain is known to contribute to delirium [11]. Morrison et al. reported that extreme pain is highly related to delirium [9], Inouye et al. stated that 30$40 \%$ of delirium can be prevented by treating risk factors [12]. In the degree of pain assessed at POD 1, 2 and 3, the femoral nerve block group showed significantly better results. This may be due to not only the regional block being performed exactly on the desired site by ultrasound but also the effect of sustained anesthetic agent through the catheter.

Various studies are being conducted to reduce delirium. Research into pharmacologic agents using antipsychotics and anticholinergics is ongoing $[13,14]$. Larsen and Sieber et al. reported that antipsycotics and anesthetic agents could reduce the incidence of delirium [15], but Gamberini et al. reported that anticholinergics had no effect on the reduction of delirium [14]. The consequences of using the drug are not yet clear. White et al. reported that $36 \%$ of hip patients had a renal dysfunction, which is a high-risk factor for morphine accumulation that induces respiratory tract infection and hypoxia [16]. For these reasons, Association of Anaesthetists of Great Britain and Ireland (AAGBI) recommends caution in the use of opiate in older hip fracture patients, and some studies have suggested that opiate is associated with delirium in older patients [17]. In this study, opioid usage quantified by Fentanyl also showed a significantly lower usage in the block group. This may not only reduce the risk of drug side effects of opioid including fentanyl, but also contribute to the low incidence of delirium. However, the mechanism of delirium is not yet understood, further research on this mechanism is needed.

Pain control through the catheter can be performed under an ultrasound guide, which results in a continuous effect by placing the catheter tip in the correct position. It is less likely to have systematic effects including the contralateral lower extremities. The low delirium incidence of femoral nerve block in this study was attributed to the combination of acute pain control and decreased opioid usage. This study has a few limitations. For one, we could not control pain perfectly because only femoral nerve block was used to relieve pain from hip fracture. In addition, oral NSAIDs were used in addition to the nerve block, which limits the examination of the direct association between nerve block and delirium. Thus, subsequent studies should examine pain control with other nerve blocks to investigate their associations with the incidence of delirium.

\section{Conclusion}

This study aimed to assess postoperative pain control and changes in the amount of opioid used as risk factors for postoperative delirium in hip fracture patients, and we confirmed that concomitant use of femoral nerve block and PCA is associated with relief of postoperative pain and lower incidence of postoperative delirium compared to when PCA was used alone.

\section{Disclosure statement}

The authors declare that there are no potential conflicts of interest. 


\section{References}

1. Flinn DR, Diehl KM, Seyfried LS, Malani PN (2009) Prevention, Diagnosis, and Management of Postoperative Delirium in Older Adults. J Am Coll Surg 209 (2): 261-268.

2. Inouye SK (2000) Prevention of delirium in hospitalized older patients: Risk factors and targeted intervention strategies. Ann Med 32 (4): 257 263.

3. Umarji SIM, Lankester BJA, Prothero D, Bannister GC (2000) Delirium Is Independently Associated with Poor Functional Recovery After Hip Fracture. J Am Geriatr Soc 48 (6): 618-624

4. Edlund A, Gustafson Y (2001) Delirium Before and After Operation for Femoral Neck Fracture :1335-1340.

5. Lynch EP, Lazor MA, Gellis JE, Orav J, Goldman L, et al. (1998) The of impact postoperative pain on the development of postoperative delirium. Anesth Analg 86(4): 781-785.

6. Clegg A,Young JB (2011) Which medications to avoid in people at risk of delirium: A systematic review. Age Ageing 40 (1): 23-29.

7. Patanwala AE, Duby J, Waters D, Erstad BL (2007) Opioid conversions in acute care. Ann Pharmacother 41 (2): 255-267.

8. Abou-setta AM, Beaupre LA, Rashiq S, Dryden DM, Hamm MP (2011) Review Annals of Internal Medicine Comparative Effectiveness of Pain Management Interventions for Hip Fracture: A Systematic Review.

9. Morrison RS, Jay Magaziner, Marvin Gilbert, Kenneth J Koval, Mary Ann Mc Laughlin, et al. (2003) Relationship Between Pain and Opioid Analgesics on the Development of Delirium Following Hip Fracture 58 (1): 76-81.

ISSN: 2574-1241

DOI: 10.26717/BJSTR.2020.28.004684

Jong seok Baik. Biomed J Sci \& Tech Res

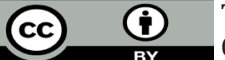

This work is licensed under Creative Commons Attribution 4.0 License

Submission Link: https://biomedres.us/submit-manuscript.php
10. Mosk, Marnix Mus, Jos Pam Vroemen, Tjeerd van der Ploeg, Dagmar I Vos, et al. (2017) Dementia and delirium, the outcomes in elderly hip fracture patients. Clin Interv Aging 12: 421-430.

11. Uysal AI, Bașak Altıparmak, Eylem Yașar, Mustafa Turan, Umut Canbek , et al. (2020) The effects of early femoral nerve block intervention on preoperative pain management and incidence of postoperative delirium geriatric patients undergoing trochanteric femur fracture surgery: A randomized controlled trial. Ulus Travma ve Acil Cerrahi Derg 26 (1): 109-114.

12. Inouye SK, Westendorp RGJ, Saczynski JS (2014) Delirium in elderly people. The Lancet.

13. Randomized A, Susan E Kelly, Theodore A Stern, Robert H Bode Jr Lori Lyn Price, et al. (2020) Administration of Olanzapine to Prevent Postoperative Delirium in Elderly Joint-Replacement Patients. Psychosomatics 51 (5): 409-418.

14. Gamberini M, Daniel Bolliger, Giovanna A Lurati Buse, Christoph S Burkhart, Martin Grapow, et al. (2009) Rivastigmine for the prevention of postoperative delirium in elderly patients undergoing elective cardiac surgery. A randomized controlled trial 37(5)

15. Sieber, Khwaji J Zakriya, Allan Gottschalk, Mary-Rita Blute, Hochang B Lee, et al. (2010) Sedation Depth During Spinal Anesthesia and the Development of Postoperative Delirium in Elderly Patients Undergoing Hip Fracture Repair

16. White SM, Rashid N, Chakladar A (2009) An analysis of renal dysfunction in 1511 patients with fractured neck of femur : the implications for perioperative analgesia : 1061-1065

17. Griffiths R, Alper J, Beckingsale A, Goldhill D, Heyburn G, et al. (2012) Management of proximal femoral fractures 2011: 85-98.

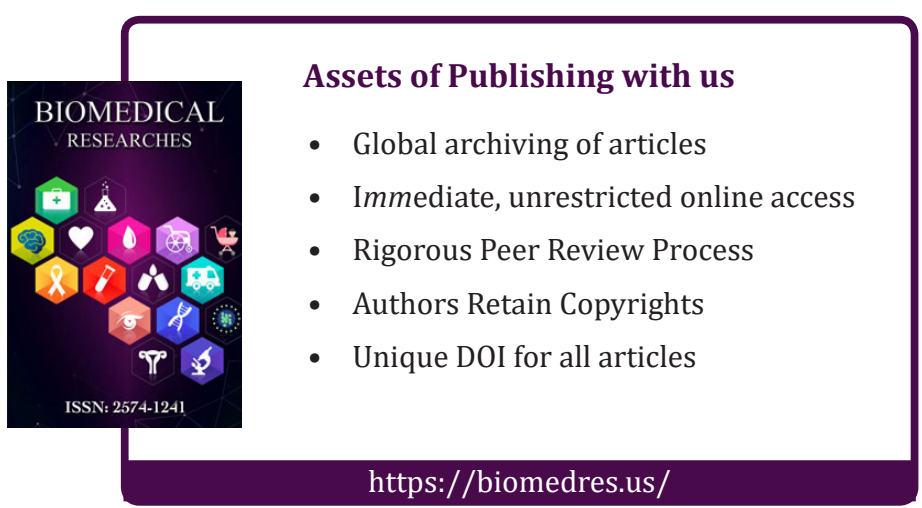

